\title{
Activating mu-opioid receptors in the spinal cord mediates the cardioprotective effect of remote preconditioning of trauma
}

\author{
Bin Mei ${ }^{1}$, Wanhong $\mathrm{Li}^{1}$, Xinqi Cheng ${ }^{1}$, Xuesheng Liu' ${ }^{1}$, Erwei Gu${ }^{1}$, Ye Zhang ${ }^{2}$
}

${ }^{1}$ Department of Anesthesiology, the First Affiliated Hospital of

Anhui Medical University, Hefei City, Anhui Province, China

${ }^{2}$ Department of Anesthesiology, the Second Affiliated Hospital of

Anhui Medical University, Hefei City, Anhui Province, China

\begin{abstract}
Background: Remote precoditioning of trauma (RPCT) confers cardioprotective effects against myocardial ischemia/reperfusion injury, which are mediated by spinal opioid receptors. The aim of this study was to identify the roles of opioid receptor subtypes in the cardioprotective effect of RPCT and possible mechanisms.

Methods: In this study, 192 Sprague-Dawley rats were allocated to 12 groups. Except for the sham group, rats in all groups were subjected to myocardial ischemia reperfusion. Rats in the ischemia precondition (IPC) group were treated with IPC. In the RPCT groups, an abdominal incision was made 15 min before inducing ischemia. The selective delta-, kappa-, and mu-opioid receptor antagonists were administered to groups of animals receiving RPCT, respectively. Data were collected for myocardial infarct size, intercellular adhesion molecule 1 (ICAM-1), plasma cardiac troponin I (cTnI) concentrations, activation of protein kinase C epsilon (PKCE) in myocardial cell membranes, and adenosine release in the spinal cord.

Results: Compared with the control groups, infarct size, plasma concentrations of cTnI, and myocardial ICAM-1 expression were significantly lower, while adenosine release and PKCE activation were enhanced in the IPC and RPCT groups. Compared with the RPCT group, infarct size, plasma cTnI concentration, and myocardial ICAM-1 expression were greater and adenosine release and PKCE activation were reduced in the mu-opioid receptor antagonist plus RPCT group.

Conclusions: The spinal mu-opioid receptor mediated the cardiac protective effect of RPCT. The mechanism may be enhanced by adenosine release in the spinal cord and PKCE activation in the myocardium, thereby inhibiting inflammation induced by ischemia/reperfusion injury. (Cardiol J 2017; 24, 3: 314-323)
\end{abstract}

Key words: opioid receptor, remote preconditioning of trauma, myocardial reperfusion injury, spinal cord, adenosine, inflammation

\section{Introduction}

In 2004, Ren et al. [1] first described the concept of remote preconditioning of trauma (RPCT) in a mouse model. They found that the creation of an abdominal incision before cardiac ischemia/reperfusion (IR) reduced the rate of associated myocardial injury. Peripheral nociception and neurogenic activation of protein kinase $\mathrm{C}$ epsilon $(\mathrm{PKC} \varepsilon$ ) was found to mediate this cardioprotective effect [2].

Address for correspondence: Dr Erwei Gu, Department of Anesthesiology, the first affiliated hospital of Anhui Medical University, Hefei city, Anhui province, China, No. 218 Jixi road, Postcode: 230022, tel: +8655162922057 , fax: +8655162922057, e-mail: ay_mz_902@163.com 


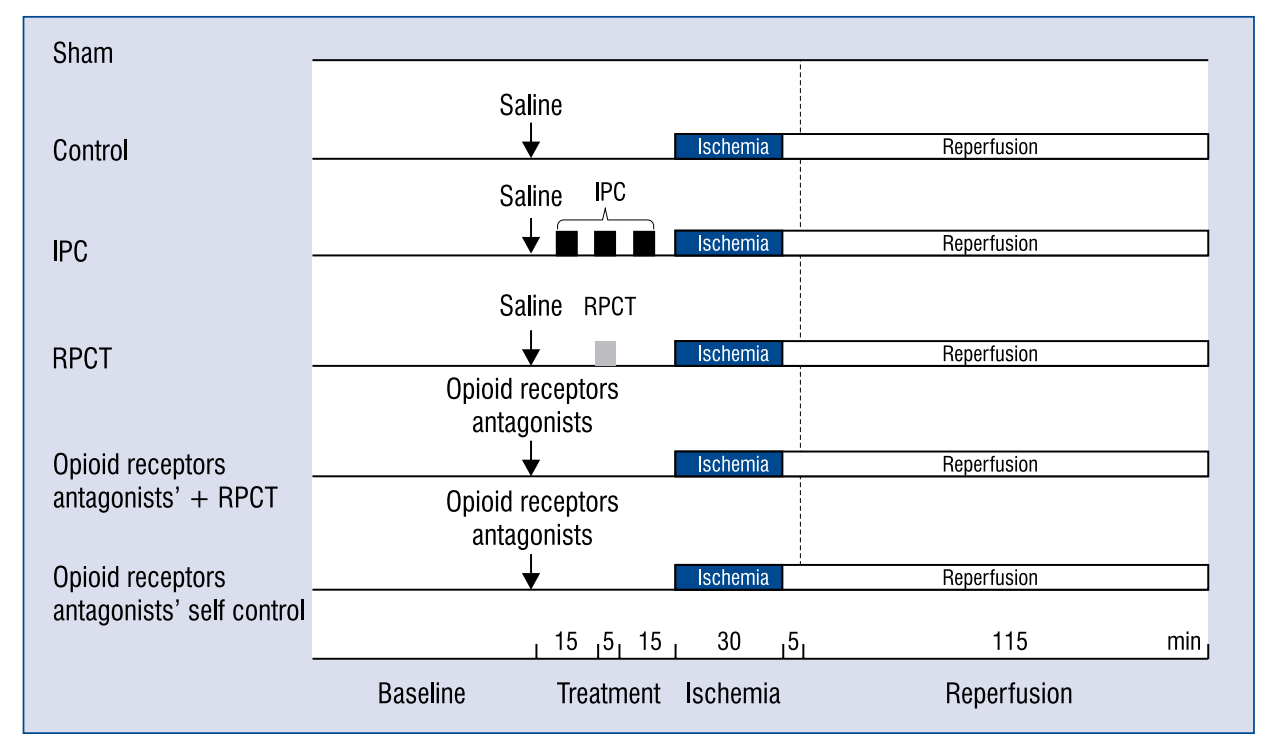

Figure 1. The schematic diagram for the experiment protocol. Sham group received no occlusion or reperfusion; all other groups were subjected to $30 \mathrm{~min}$ ischemia and $120 \mathrm{~min}$ reperfusion. Control groups received intrathecal administration of $10 \mu \mathrm{L}$ normal saline plus induction of ischemia/reperfusion (IR) injury. The ischemia preconditiong (IPC) group received three cycles of $5 \mathrm{~min}$ of ischemia followed by $5 \mathrm{~min}$ of reperfusion before IR injury plus intrathecal normal saline. In the remote precoditioning of trauma (RPCT) groups, abdominal incision was made 15 min before IR injury, plus intrathecal normal saline. In opioid receptor antagonist + RPCT groups, $15 \mathrm{nM}$ of specific opioid receptor subtype antagonist were administrated intrathecally followed by $10 \mu \mathrm{L}$ normal saline flush 10 min before abdominal incision was made. For the opioid receptor antagonist self-control groups, the protocol was the same as for the three subtype opioid receptor antagonist plus remote preconditioning of trauma groups but without remote preconditioning of trauma.

In a rat model of IR injury, we observed the cardioprotective effect of RPCT and the fact that opioid receptors in the spinal cord mediated this effect using the non-selective opioid receptor antagonist - naloxone [3]. However, results from the peripheral mechanism of RPCT study indicated that endogenous opioids made no contribution to the cardioprotective effect of RPCT [4]. The difference between opioid receptor expression in the rat myocardium and spinal cord seems to be the reason for this phenomenon. No evidence was obtained to prove the expression of mu-opioid receptors in the rat myocardium [5].

Activation of spinal cord opioid receptors with morphine was found to mediate the cardioprotective effect of RPCT against IR injury [6]. In particular, activation of the mu receptor upregulated the release of adenosine in the spinal cord [7, 8], and this effect played an essential role in modulating peripheral inflammation [9]. We hypothesize that mu receptorrelated adenosine release in the central nervous system mediates the cardioprotective effect of RPCT.

This study was conducted to further investigate the roles of opioid receptor subtypes in the mediation of the cardioprotective effect of RPCT, as well as the underlying mechanism in the spinal cord adenosine system.

\section{Methods}

The Anhui Medical University Committee on the Use of Live Animals in Teaching and Research provided ethical approval for this study (Protocol number: LLSC20150041; Approval date: 12-01-2015). Male Sprague-Dawley rats weighing 250-300 g were provided by the Anhui Medical University experimental animal center. They were housed in separate cages with a 12-h light/dark cycle and given free access to food and water.

\section{Study groups and experimental protocol}

The rats were randomly assigned to the following 12 groups ( $\mathrm{n}=24$ for control groups and RPCT groups; $\mathrm{n}=18$ for other groups) (Fig. 1):

1) Sham group: intrathecal catheter placement, heart exposure, and suturing without ischemia/reperfusion;

2,3) Control groups: intrathecal administration of $10 \mu \mathrm{L}$ normal saline plus induction of I/R. Six rats were in control group 1 , and 18 rats comprised control group 2 ;

4) Ischemia preconditioning (IPC) group: intrathecal administration of $10 \mu \mathrm{L}$ normal saline, followed by three cycles of $5 \mathrm{~min}$ ischemia and $5 \mathrm{~min}$ reperfusion before $\mathrm{I} / \mathrm{R}$; 
5,6) RPCT groups: abdominal incision $15 \mathrm{~min}$ before IR injury plus intrathecal administration of $10 \mu \mathrm{L}$ normal saline. Six rats were in RPCT group 1, and 18 rats comprised RPCT group 2;

7-9) Opioid receptor antagonist plus RPCT groups: intrathecal administration of $15 \mathrm{nM}$ selective delta (naltrindole [NTD]), kappa (nor-binaltorphimine [nor-BNI]), or mu (D-Phe-Cys-Tyr-D-Trp-Orn-Thr-Pen-ThrNH2 [CTOP]) opioid receptor antagonist (Sigma Aldrich, St. Louis, USA), followed by $10 \mu \mathrm{L}$ normal saline flush 15 min before abdominal incision. The doses of these antagonists were selected on the basis of the previous study [21];

10-12) Opioid receptor antagonist self-control groups: same protocols as for groups $5-7$, but without RPCT.

\section{Intrathecal catheter placement}

Catheters were inserted according to methods described by Yaksh and Rudy [10], and as previously described. Animals were anesthetized by intraperitoneal injection of pentobarbitone $(80 \mathrm{mg} /$ $/ \mathrm{kg}$ for control group 1 and RPCT group $1,50 \mathrm{mg} / \mathrm{kg}$ for other groups). After skin sterilization, a small polyethylene-10 catheter (external diameter, $0.8 \mathrm{~mm}$; internal diameter, $0.4 \mathrm{~mm}$; Smiths Medical International, Kent, UK) was inserted through a puncture into the atlanto-occipital membrane, then advanced $4 \mathrm{~cm}$ to the level of the thoracic spinal cord. The intrathecal position of the catheter was confirmed via backflow of cerebrospinal fluid. After insertion, wounds were closed and the animals returned to their cages. Subsequently, the rats were monitored for 3 days. Thirty-one animals developed motor or sensory deficits during this period and were excluded from the study.

\section{Ischemia/reperfusion injury preparation}

As described previously [11], after a minimum of 3-day recovery from intrathecal catheter placement, animals were anesthetized by intraperitoneal pentobarbitone injection $(80 \mathrm{mg} / \mathrm{kg}$ for control group 1 and RPCT group $1,50 \mathrm{mg} / \mathrm{kg}$ for other groups). Anesthesia was maintained with repeat doses of $25 \mathrm{mg} / \mathrm{kg}$ intraperitoneal pentobarbitone every 60-90 min. Tracheotomy was performed and mechanical ventilation was commenced with a rodent respirator (Harvard Apparatus, Boston, MA, USA) using ambient air at a rate of 60 -70 breaths/min. Body temperature was maintained using a heating pad. For direct arterial blood pres- sure monitoring, a heparinized $(50 \mathrm{U} / \mathrm{mL}$ heparin saline) polyethylene catheter (external diameter, $1.0 \mathrm{~mm}$; internal diameter, $0.5 \mathrm{~mm}$; Smiths Medical International) was inserted into the right carotid artery and connected to a pressure transducer. The catheter was flushed with $0.5 \mathrm{~mL}$ heparin saline $(50 \mathrm{U} / \mathrm{mL})$ every $30 \mathrm{~min}$ via a three-way tube. Lead II of the electrocardiogram was monitored using subcutaneous stainless-steel electrodes connected to a monitoring system (ML750 PowerLab/4SP with ML T0380 reusable blood pressure transducer; AD Instruments, Colorado Springs, CO, USA). For saline infusion, a polyethylene catheter was inserted into the right jugular vein. The heart was exposed at the fifth intercostal space after left thoracotomy was performed. After removing the pericardium, a 6-0 suture (Jinhuan medical company, Shanghai, China) loop and snare occluder was placed at the origin of the left main coronary artery. Regional myocardial ischemia was performed by pulling the snare and securing the threads with a mosquito hemostat. Ischemia was confirmed by the appearance of myocardial cyanosis in the distribution of the left coronary artery, a decrease in mean arterial blood pressure (MAP), and electrocardiographic ST segment changes. Data from 24 rats in which severe hypotension (MAP $<30 \mathrm{~mm}$ $\mathrm{Hg}$ ) or intractable ventricular fibrillation occurred were excluded from the study.

\section{Remote preconditioning of trauma}

An abdominal incision was used as the non-ischemic stimulus for RPCT, as described previously [2]. The incision (length, $2 \mathrm{~cm}$ ) was made along the abdominal midline through the skin, subcutaneous tissue, fat, muscle, and peritoneum. It was closed immediately using 7-0 polypropylene sutures (Jinhuan medical company, Shanghai, China).

\section{Hemodynamics record}

As shown in Figure 1, hemodynamic values, including heart rate (HR), MAP, and rate pressure product (RPP), were collected at the timepoints of baseline, treatment, ischemia and reperfusion.

\section{Determination of myocardial infarct size and plasma concentration of cardiac troponin I}

After completion of the reperfusion period, hearts of 6 animals in each group were excised and transferred to a Langendorff apparatus, perfused with normal saline for $1 \mathrm{~min}$ at a pressure of $100 \mathrm{~cm}$ $\mathrm{H}_{2} \mathrm{O}$ to flush out residual blood. The snare was securely re-tightened and $0.25 \%$ Evans Blue dye was injected to stain the normally perfused region. 
This procedure allowed visualizing the normal, non-ischemic region and the area at risk. The heart was then frozen and cut into 2 -mm slices. Thereafter, the slices were stained by incubation at $37^{\circ} \mathrm{C}$ for $20 \mathrm{~min}$ in $1 \%$ 2,3,5-triphenyltetrazolium (Sigma Aldrich, St. Louis, USA) in a phosphate buffer at $\mathrm{pH}$ 7.4. This was followed by immersion in $10 \%$ formalin for $20 \mathrm{~min}$ to enhance contrast of the stain. The infarct size (IS) was quantified as a percentage of the area at risk (AAR) using a previously described computerized planimetric technique (SigmaScan 4.0; Systat Software Inc, Richmond, CA, USA) [11]. Arterial blood samples of these 6 animals $(5 \mathrm{~mL})$ were obtained at the end of reperfusion and centrifuged at 3,000 rpm for $10 \mathrm{~min}$ to obtain plasma. The plasma cardiac troponin I (cTnI) concentration was determined as previously described [12], using a commercially available assay kit (R\&D Systems, Minneapolis, USA).

\section{Determination of myocardial intercellular adhesion molecule 1 concentration}

Immediately after reperfusion, the hearts of another 6 animals (not including control group 1 and RPCT group 1) were removed. Myocardial tissue in the approximate area supplied by the left coronary artery was excised and frozen using liquid nitrogen. The intercellular adhesion molecule 1 (ICAM-1) concentration was determined as described previously [13], using a commercially available assay kit (R\&D Systems, Minneapolis, USA).

\section{Examination of protein kinase $\mathrm{C}$ epsilon activation in myocardial cell membranes}

The remaining 6 animals (not including control group 1 and RPCT group 1) were used for PKC $\varepsilon$ activation analysis and adenosine release detection (see below). For analysis of $\mathrm{PKC} \varepsilon$ activation in myocardial cell membranes, the heart was excised and left ventricular (tissue from the area at risk) samples were collected 5 min after the onset of reperfusion. These tissues were frozen using liquid nitrogen immediately before storage at $-80^{\circ} \mathrm{C}$. Frozen tissues were powdered and homogenized in buffer A (5 mM Tris, $4 \mathrm{mM}$ ethylene glycol tetraacetic acid, $2 \mathrm{mM}$ ethylenediaminetetraacetic acid [EDTA], $5 \mathrm{mM}$ dithothreitol, $1 \mathrm{mM}$ phenylmethyl sulfonyl fluoride, and EDTA-free protease inhibitor [1 tablet/10 mL]). The homogenate was centrifuged at $100,000 \mathrm{~g}$ at $4^{\circ} \mathrm{C}$ for $30 \mathrm{~min}$ to discard the supernatant. The pellet was collected and rehomogenized with buffer A, containing $1 \%$ Triton X, by incubation on ice for $20 \mathrm{~min}$, then centrifuged at $100,000 \mathrm{~g}$ at $4^{\circ} \mathrm{C}$ for $30 \mathrm{~min}$. The supernatant was considered a membrane-associated fraction. Protein concentration was determined by assay (Bio-Rad, Hercules, CA, USA). PKC $\varepsilon$ was detected as described previously [2], by sodium dodecyl sulfate-polyacrylamide gel electrophoresis using an antibody obtained from Cell Signaling Technology (Boston, MA, USA). Equal protein loading was confirmed using glyceraldehyde-3-phosphate dehydrogenase. Relative densitometry was performed using the Quantity One software package (Bio-Rad).

\section{Detection of adenosine release in the spinal cord}

For the analysis of adenosine release, spinal cord tissue from the T1-T5 region was collected $5 \mathrm{~min}$ after the onset of reperfusion. Tissue samples were homogenized in ice-cold perchloric acid (6\%) and centrifuged at $16,000 \mathrm{~g}$ at $9^{\circ} \mathrm{C}$ for $5 \mathrm{~min}$. The supernatant was removed and neutralized with $1.65 \mathrm{~mol} / \mathrm{L}$ potassium carbonate, then centrifuged as described above, and the supernatant was removed and then frozen in liquid nitrogen.

Adenosine levels in tissue extracts were determined by high-performance liquid chromatography (HPLC) coupled with ultraviolet detection, using a method modified from Hagberg et al. [14] Samples $(20 \mu \mathrm{L})$ were passed through a $0.45-\mu \mathrm{m}$ filter, injected via an autosampler (717Plus; Waters, Milford, MA, USA), and eluted ( $1 \mathrm{~mL} / \mathrm{min})$ using $50 / 4 \mathrm{mmol} / \mathrm{L} \mathrm{NaH}_{2} \mathrm{PO}_{4} / \mathrm{Na}_{2} \mathrm{HPO}_{4}$ (pH 5.8 at room temperature). Separation was achieved with a $\mathrm{C} 18$ column (Waters), while temperature was maintained at $35^{\circ} \mathrm{C}$ with a column heater compartment. Peaks were detected at $260 \mathrm{~nm}$ using a Waters 2487 dual-channel absorbance detector, and results were quantified by comparing peak areas with known standards using Breeze 3.30 software (Waters). Adenosine peaks were identified by comparison of retention times and with standard substances with known adenosine quantities (Sigma Aldrich, St. Louis, USA).

\section{Statistical analysis}

Data were expressed as mean \pm standard deviation and analyzed using the Prism software package (version 4.0; GraphPad Software, San Diego, CA, USA). Hemodynamic data were examined using two-way analysis of variance with Bonferroni correction for multiple comparisons when significant $F$ ratios were obtained. IS/AAR was compared among groups using analysis of variance with the post-hoc Student-Newman-Keuls test for multiple comparisons. Statistical differences were considered significant when $\mathrm{p}$ values were $<0.05$. 


\section{Results}

\section{Hemodynamics}

Compared with baseline values, HR, MAP, and RPP decreased significantly after $30 \mathrm{~min}$ ischemia and $120 \mathrm{~min}$ reperfusion in all groups except the sham group ( $p<0.05$; Table 1$)$. These values were significantly lower in all groups apart from the sham group at these timepoints $(\mathrm{p}<0.05)$.

\section{Myocardial infarct size and cardiac troponin I concentration}

Compared with the sham group, IR injury markedly increased the cTnI concentration $(\mathrm{p}<0.001$; Table 2). IPC significantly reduced the IS/AAR $(\mathrm{p}<0.001$; Table 2; Fig 2) and the cTnI concentration compared with control group 2 ( $\mathrm{p}<0.001)$. Similarly, compared with control groups, RPCT not only reduced the IS/AAR $(p<0.01)$ and the $c$ TnI concentration $(p<0.01)$ when rats were anesthetized with $80 \mathrm{mg} / \mathrm{kg}$ pentobarbitone, but also reduced the IS/AAR $(\mathrm{p}<0.001)$ and the $\mathrm{c}$ TnI concentration $(\mathrm{p}<0.01)$ when rats were anesthetized using $50 \mathrm{mg} / \mathrm{kg}$ pentobarbitone. CTOP eliminated the effect of RPCT on IS/AAR ( $<<0.001)$ and the concentration of $\mathrm{cTnI}(\mathrm{p}<0.05)$, but no differences between the RPCT group 2 and the NTD + RPCT or nor-BNI + RPCT group were observed. In addition, no difference was observed between control group 2 and the three opioid receptor antagonist self-control groups.

\section{Myocardial intercellular adhesion molecule 1 expression}

Compared with the sham group, IR injury markedly increased ICAM-1 expression $(\mathrm{p}<0.001$; Table 2). IPC significantly reduced ICAM-1 expression compared with control group $2(\mathrm{p}<0.001)$. Similarly, ICAM-1 expression was lower in RPCT group 2 than in control group $2(\mathrm{p}<0.001)$. This expression was significantly higher in the CTOP + + RPCT group than in the RPCT group $(\mathrm{p}<0.001)$, but no differences between RPCT group 2 and the $\mathrm{NTD}+\mathrm{RPCT}$ or nor-BNI + RPCT group were observed. In addition, no differences were observed between the control group 2 and the three opioid receptor antagonist self-control groups.

\section{Protein kinase $\mathrm{C}$ epsilon activation in myocardial cell membrane \\ Ischemia/reperfusion injury increased $\mathrm{PKC} \varepsilon$ activation in the myocardial cell membrane com- pared with the sham group ( $\mathrm{p}<0.05$; Fig 3 ). Com- pared with control group $2, \mathrm{PKC} \varepsilon$ activation was}

further enhanced in the IPC group and RPCT group 2 (both $\mathrm{p}<0.01$ ). Among opioid receptor antagonists, only CTOP eliminated the effect observed in RPCT group $2(\mathrm{p}<0.05)$. No differences were observed between control group 2 and the three opioid receptor antagonist self-control groups.

\section{Adenosine release in spinal cord}

An adenosine peak was detected via HPLC at nearly 10 min after onset of detection (Fig. 4). IR injury increased the release of adenosine in the spinal cord, but this difference was not significant. Adenosine release observed in the IPC group and RPCT group 2 was greater than in control group 2 (both $\mathrm{p}<0.05$; Fig. 5). Among opioid receptor antagonists, only CTOP eliminated the enhancement observed in RPCT group $2(\mathrm{p}<0.05)$. No differences were observed between the control group 2 and the three opioid receptor antagonist self-control groups.

\section{Discussion}

The present data suggest that RPCT had a cardioprotective effect against IR injury by means of activation of mu-opioid receptors in the spinal cord in the rat model. Enhancement of adenosine release in the central nervous system mediated the cardioprotective effect of RPCT. In the peripheral nervous system, $\mathrm{PKC} \varepsilon$ activation and inhibition of inflammation also contributed to this mechanism.

Remote preconditioning of trauma is a nonischemic cardioprotective method, first reported in 2004 [1], and confirmed by animal studies in mouse and rat myocardial ischemia reperfusion models $[15,16]$. However, in previous studies, depth of anesthesia seemed insufficient, which weakened the clinical value of these studies [17]. In the current study, we used the IPC group as the positive control and anesthetized animals using two different dosages of pentobarbitone. We found that RPCT reduced the size of infarcts and elevated cTnI concentration induced by IR injury, which is irrelevant to anesthesia depth.

In our previous study, we found that intrathecal administration of the non-selective opioid receptor antagonist naloxone before RPCT eliminated the cardioprotective effect conferred by RPCT [3]. To further identify the involvment of opioid receptor subtypes in this mediation, we tested three opioid receptor antagonists (NTD, nor-BNI, and CTOP) in the present study. Among opioid receptors in the spinal cord, only the mu receptors mediated the protective effect of RPCT. This result differed from 
Table 1. Hemodynamics for all groups at baseline treatment, $30 \mathrm{~min}$ of ischemia and $120 \mathrm{~min}$ of reperfusion.

\begin{tabular}{|c|c|c|c|c|}
\hline & Baseline & Treatment & $30 \mathrm{~min}$ ischemia & $120 \mathrm{~min}$ reperfusion \\
\hline \multicolumn{5}{|l|}{ Heart rate [bpm] } \\
\hline Sham & $385 \pm 43$ & $378 \pm 33$ & $374 \pm 39$ & $365 \pm 38$ \\
\hline Control 1 & $372 \pm 57$ & $361 \pm 46$ & $331 \pm 44^{* \#}$ & $325 \pm 59^{* \#}$ \\
\hline Control 2 & $389 \pm 43$ & $376 \pm 34$ & $343 \pm 39^{* \#}$ & $342 \pm 37^{* \#}$ \\
\hline IPC & $386 \pm 32$ & $351 \pm 21$ & $337 \pm 33^{* \#}$ & $331 \pm 29^{* \#}$ \\
\hline RPCT 1 & $375 \pm 52$ & $369 \pm 43$ & $343 \pm 52^{* \#}$ & $336 \pm 61^{* \#}$ \\
\hline RPCT 2 & $381 \pm 38$ & $377 \pm 28$ & $356 \pm 35^{* \#}$ & $348 \pm 37^{* \#}$ \\
\hline CTOP+RPCT & $396 \pm 37$ & $382 \pm 27$ & $334 \pm 35^{* \#}$ & $344 \pm 33^{* \#}$ \\
\hline nor-BNI+RPCT & $379 \pm 36$ & $376 \pm 33$ & $340 \pm 35^{* \#}$ & $330 \pm 32^{* \#}$ \\
\hline NTD+RPCT & $387 \pm 39$ & $379 \pm 22$ & $340 \pm 37^{* \#}$ & $337 \pm 34^{* \#}$ \\
\hline $\mathrm{CTOP}+\mathrm{I} / \mathrm{R}$ & $391 \pm 37$ & $377 \pm 26$ & $347 \pm 37^{* \#}$ & $342 \pm 32^{* \#}$ \\
\hline nor-BNI+I/R & $382 \pm 39$ & $376 \pm 29$ & $352 \pm 35^{* \#}$ & $348 \pm 35^{* \#}$ \\
\hline NTD + l/R & $395 \pm 28$ & $381 \pm 19$ & $351 \pm 28^{* \#}$ & $345 \pm 23^{* \#}$ \\
\hline \multicolumn{5}{|c|}{ Mean arterial pressure $[\mathrm{mm} \mathrm{Hg}]$} \\
\hline Sham & $99 \pm 15$ & $91 \pm 10$ & $88 \pm 13$ & $88 \pm 12$ \\
\hline Control 1 & $100 \pm 19$ & $92 \pm 11$ & $76 \pm 13^{* \#}$ & $79 \pm 16^{* \#}$ \\
\hline Control 2 & $98 \pm 13$ & $89 \pm 14$ & $74 \pm 11^{* \#}$ & $82 \pm 11^{* \#}$ \\
\hline IPC & $98 \pm 12$ & $87 \pm 9$ & $71 \pm 8^{* \#}$ & $79 \pm 13^{* \#}$ \\
\hline RPCT 1 & $95 \pm 15$ & $92 \pm 14$ & $69 \pm 12^{* \#}$ & $71 \pm 11^{* \#}$ \\
\hline RPCT 2 & $97 \pm 13$ & $91 \pm 11$ & $75 \pm 8^{* \#}$ & $78 \pm 12^{* \#}$ \\
\hline CTOP+RPCT & $93 \pm 13$ & $89 \pm 12$ & $72 \pm 10^{* \#}$ & $80 \pm 10^{* \#}$ \\
\hline nor-BNI+RPCT & $97 \pm 9$ & $92 \pm 9$ & $74 \pm 9^{* \#}$ & $82 \pm 9^{* \#}$ \\
\hline NTD+RPCT & $91 \pm 12$ & $89 \pm 13$ & $70 \pm 9^{* \#}$ & $80 \pm 9^{* \#}$ \\
\hline CTOP+I/R & $93 \pm 11$ & $88 \pm 11$ & $69 \pm 10^{* \#}$ & $79 \pm 10^{* \#}$ \\
\hline nor-BNI+I/R & $94 \pm 13$ & $90 \pm 12$ & $71 \pm 9^{* \#}$ & $79 \pm 9^{* \#}$ \\
\hline NTD+l/R & $94 \pm 11$ & $89 \pm 11$ & $71 \pm 11^{* \#}$ & $81 \pm 11^{* \#}$ \\
\hline \multicolumn{5}{|c|}{ Rate pressure product $[\mathrm{mm} \mathrm{Hg} / \mathrm{min} / 1000]$} \\
\hline Sham & $39 \pm 10$ & $35 \pm 6$ & $33 \pm 8$ & $32 \pm 8$ \\
\hline Control 1 & $37 \pm 10$ & $35 \pm 5$ & $25 \pm 7^{* \#}$ & $26 \pm 4^{* \#}$ \\
\hline Control 2 & $39 \pm 9$ & $34 \pm 8$ & $26 \pm 6^{* \#}$ & $28 \pm 7^{* \#}$ \\
\hline IPC & $38 \pm 8$ & $31 \pm 4$ & $23 \pm 5^{* \#}$ & $26 \pm 6^{* \#}$ \\
\hline RPCT 1 & $36 \pm 9$ & $34 \pm 6$ & $25 \pm 8^{* \#}$ & $24 \pm 8^{* \#}$ \\
\hline RPCT 2 & $37 \pm 9$ & $35 \pm 7$ & $27 \pm 6^{* \#}$ & $28 \pm 7^{* \#}$ \\
\hline CTOP+RPCT & $37 \pm 9$ & $34 \pm 7$ & $26 \pm 6^{* \#}$ & $28 \pm 6^{* \#}$ \\
\hline nor-BNI+RPCT & $37 \pm 7$ & $34 \pm 6$ & $25 \pm 5^{* \#}$ & $27 \pm 6^{* \#}$ \\
\hline NTD+RPCT & $36 \pm 8$ & $34 \pm 7$ & $24 \pm 6^{* \#}$ & $27 \pm 5^{* \#}$ \\
\hline CTOP+I/R & $37 \pm 8$ & $34 \pm 6$ & $24 \pm 6^{* \#}$ & $27 \pm 6^{* \#}$ \\
\hline nor-BNI+l/R & $36 \pm 9$ & $34 \pm 7$ & $25 \pm 6^{* \#}$ & $28 \pm 6^{* \#}$ \\
\hline NTD + l/R & $37 \pm 7$ & $34 \pm 6$ & $25 \pm 6^{* \#}$ & $28 \pm 6^{* \#}$ \\
\hline
\end{tabular}

${ }^{*} p<0.05$ vs. baseline; ${ }^{*} p<0.05$ vs. sham group; abbreviations - see text

Li's finding, which indicated that all three opioid receptor subtypes mediated the protective effect of intrathecal morphine preconditioning [6]. This difference can be explained by the potential mecha- nism of RPCT and the roles of spinal cord opioid receptor subtypes in the modulation of nociceptive stimulation. The greatest difference between the present study and our previous research is that 
Table 2. Infarct size, plasma concentration of cardiac troponin I (cTnl) and expression of myocardial intercellular adhesion molecule 1 (ICAM-1).

\begin{tabular}{|c|c|c|c|c|c|c|}
\hline Group & $\begin{array}{c}\text { LV+RV } \\
{\left[\mathrm{cm}^{3}\right]}\end{array}$ & $\begin{array}{c}\text { Area at risk } \\
{\left[\mathrm{cm}^{3}\right]}\end{array}$ & $\begin{array}{c}\text { Infarct size } \\
{\left[\mathrm{cm}^{3}\right]}\end{array}$ & IS/AAR & $\begin{array}{c}\text { cTnl } \\
{[\mathrm{ng} / \mathrm{mL}]}\end{array}$ & $\begin{array}{l}\text { ICAM-1 } \\
{[\mathrm{pg} / \mathrm{mL}]}\end{array}$ \\
\hline Sham & $1.112 \pm 0.135$ & $0.593 \pm 0.044$ & - & - & $0.42 \pm 0.11$ & $111 \pm 9$ \\
\hline Control 1 & $1.126 \pm 0.142$ & $0.599 \pm 0.064$ & $0.317 \pm 0.041$ & $0.529 \pm 0.052$ & $1.36 \pm 0.07^{*}$ & - \\
\hline Control 2 & $0.996 \pm 0.109$ & $0.619 \pm 0.089$ & $0.336 \pm 0.039$ & $0.543 \pm 0.075$ & $1.29 \pm 0.09^{*}$ & $254 \pm 17^{*}$ \\
\hline IPC & $1.095 \pm 0.097$ & $0.601 \pm 0.054$ & $0.147 \pm 0.026^{* * *}$ & $0.245 \pm 0.036^{* * *}$ & $0.76 \pm 0.13^{* * *}$ & $132 \pm 19^{* * *}$ \\
\hline RPCT 1 & $1.014 \pm 0.079$ & $0.617 \pm 0.069$ & $0.184 \pm 0.039^{8}$ & $0.297 \pm 0.072^{8}$ & $0.92 \pm 0.15^{8}$ & - \\
\hline RPCT 2 & $1.106 \pm 0.068$ & $0.591 \pm 0.074$ & $0.171 \pm 0.024^{* * *}$ & $0.289 \pm 0.028^{* * *}$ & $0.82 \pm 0.11^{* *}$ & $158 \pm 21^{* * *}$ \\
\hline CTOP+RPCT & $0.973 \pm 0.109$ & $0.599 \pm 0.017$ & $0.296 \pm 0.047^{\# \#}$ & $0.494 \pm 0.04^{\# \#}$ & $1.13 \pm 0.16^{\#}$ & $229 \pm 24^{\# \#}$ \\
\hline nor-BNI+RPCT & $1.001 \pm 0.072$ & $0.576 \pm 0.031$ & $0.174 \pm 0.034$ & $0.302 \pm 0.057$ & $0.84 \pm 0.2$ & $151 \pm 27$ \\
\hline NTD+RPCT & $1.061 \pm 0.041$ & $0.568 \pm 0.029$ & $0.203 \pm 0.018$ & $0.357 \pm 0.016$ & $0.81 \pm 0.14$ & $146 \pm 16$ \\
\hline CTOP+I/R & $0.928 \pm 0.162$ & $0.564 \pm 0.064$ & $0.308 \pm 0.059$ & $0.546 \pm 0.075$ & $1.33 \pm 0.17$ & $273 \pm 25$ \\
\hline nor-BNI+I/R & $0.986 \pm 0.09$ & $0.621 \pm 0.052$ & $0.312 \pm 0.073$ & $0.501 \pm 0.046$ & $1.26 \pm 0.22$ & $255 \pm 12$ \\
\hline NTD+l/R & $1.203 \pm 0.089$ & $0.587 \pm 0.027$ & $0.293 \pm 0.017$ & $0.499 \pm 0.048$ & $1.17 \pm 0.07$ & $259 \pm 16$ \\
\hline
\end{tabular}

$\mathrm{LV}+\mathrm{RV}$ - the sum of left and right ventricles' area; IS/AAR — infarct size expressed as a percentage of the area at risk; " $\mathrm{p}<0.001 \mathrm{vs.} \mathrm{sham}$ group; ${ }^{8} p<0.01$ vs. control group $1 ;{ }^{* *} p<0.01$ vs. control group $2,{ }^{* * *} p<0.001$ vs. control group $2 ;{ }^{*} p<0.05$ vs. RPCT group $2,{ }^{\# \#} p<0.001$ vs. RPCT group 2; other abbreviations - see text

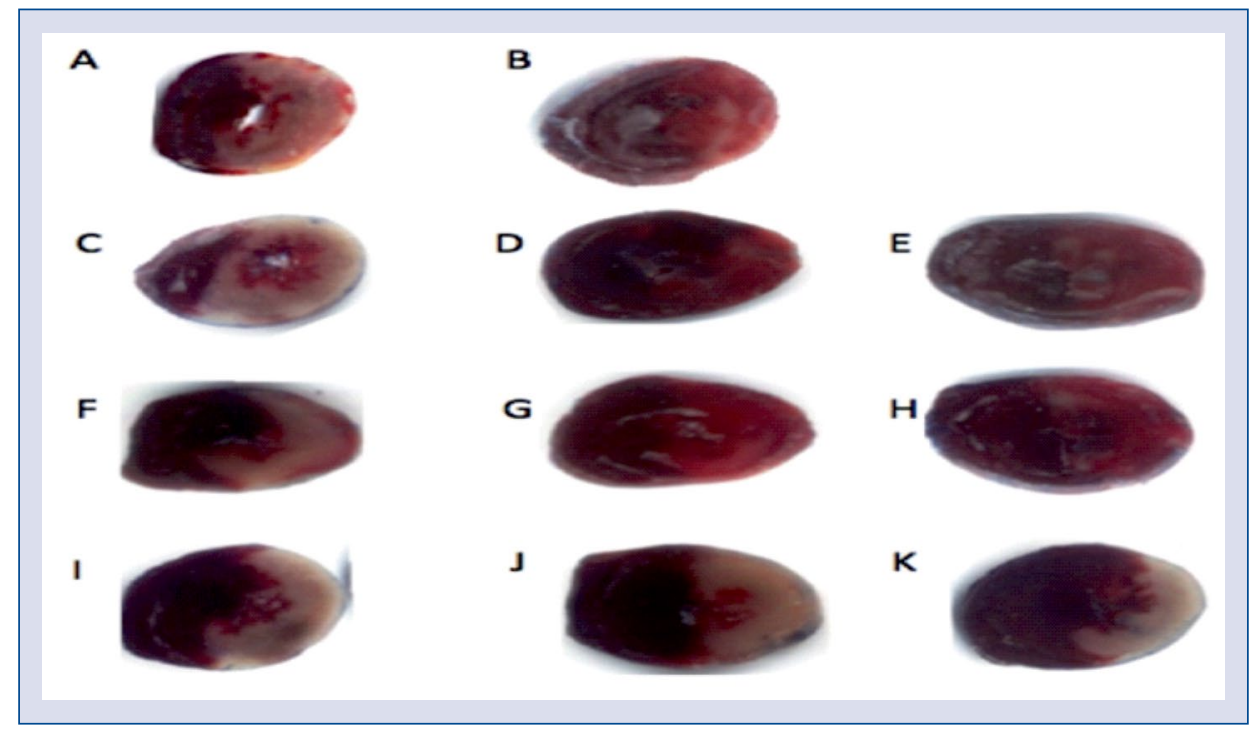

Figure 2. Pathology section of the myocardium after 2,3,5-triphenyltetrazolium chloride staining; A. Control group 1; B. RPCT group 1; C. Control group 2; D. IPC group; E. RPCT group 2; F. CTOP + RPCT group; G. Nor-BNI + RPCT group; H. NTD + RPCT group; I. CTOP group; J. Nor-BNI group; K. NTD group; abrreviations — see text.

endogenous opioid substances were investigated in the present study. RPCT can be considered a nociceptive stimulation, which could enhance release of endogenous opioid substances in the spinal cord, thereby activating the opioid receptors. In the spinal cord, among the three opioid receptor subtypes, the delta and mu receptors were reported to be the dominant modulators of excitatory substances [18].
Blockage of mu-opioid receptors in the spinal cord prevented the effects of subsequent systemic opioids [19]. With our findings in this study, we speculate that among the three opiod receptors in the spinal cord the mu-opioid receptors may be the dominant receptors involved in the cardioprotective effect of endogenous opioid substances in the spinal cord. 


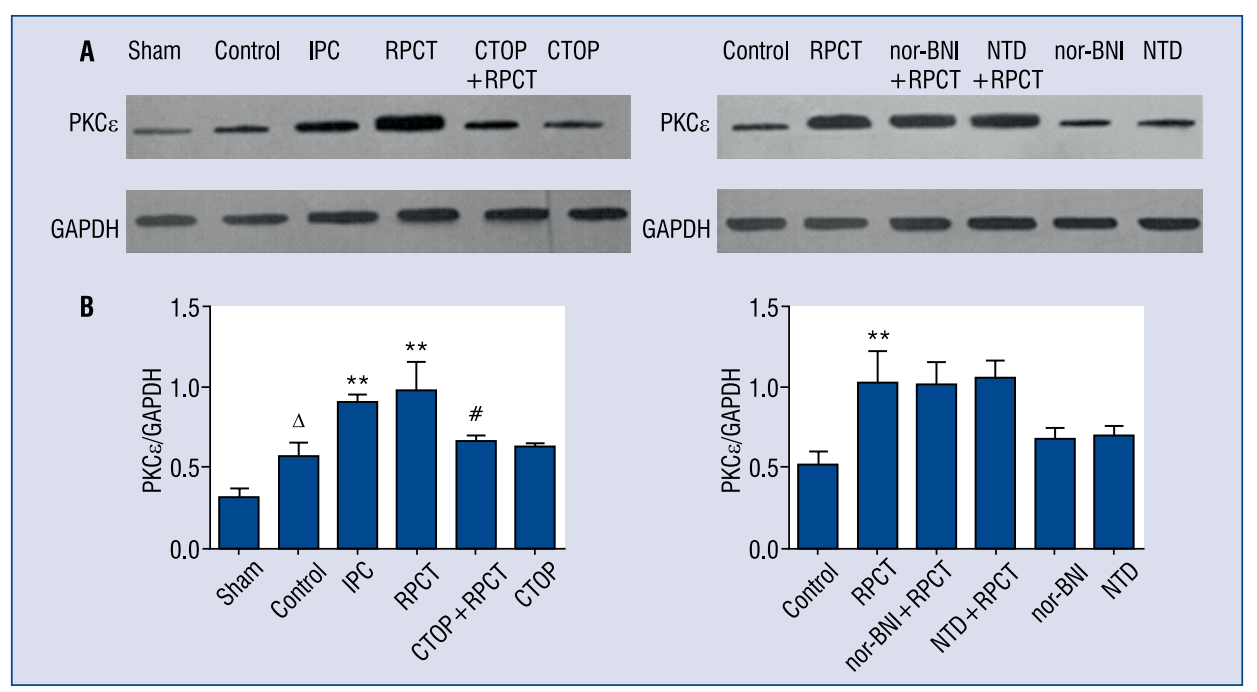

Figure 3. Western blot analysis of protein kinase C epsilon (PKC $\varepsilon$ ) in myocardial cell membrane. A. Representative quantitative immunoblots. B. PKC $\varepsilon$ band intensities were normalized to glyceraldehyde-3-phosphate dehydrogenase (GAPDH). Values are presented as mean \pm standard deviation. $N=6$ in each group; ${ }^{\wedge} p<0.05$ vs. sham group; ${ }^{* *} p<0.01$ vs. control group; ${ }^{*} p<0.05$ vs. remote precoditioning of trauma (RPCT) group; other abbreviations - see text.
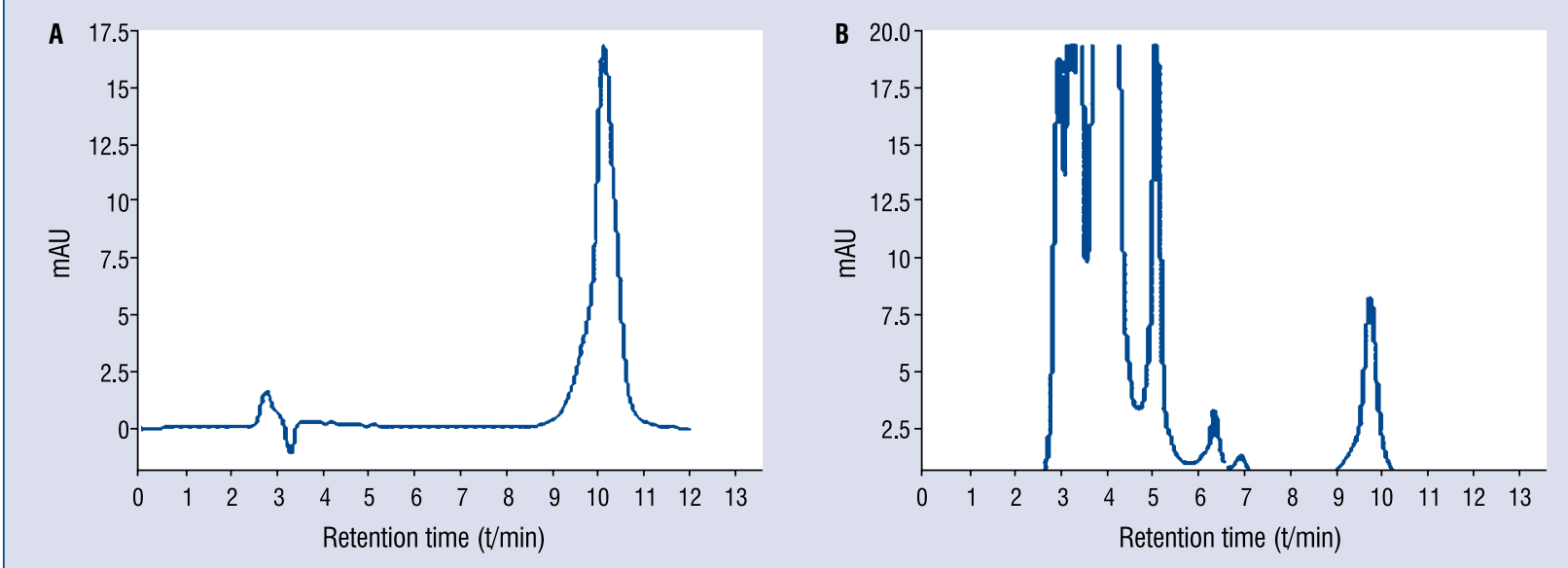

Figure 4. The chromatogram of adenosine. Adenosine peaks were identified by retention time comparisons and by standard substances with known quantities of adenosine. The adenosine peak in high-performance liquid chromatography detection appeared nearly 10 min after start; A. Standard compounds; B. Extraction of rat spinal cord; mAU - milli absorbance unit.

Several studies have proven the existence of "cross-talk" between the opioid and adenosine systems in the central nervous system. DeLander and Hopkins [20] demonstrated that adenosine receptors in the spinal cord may mediate the antinociceptive effect of intracerebroventricular or intrathecal administration of morphine. Intrathecal morphine also enhanced adenosine release from the spinal cord, which conferred the antinociceptive effect $[8,21]$. Activation of adenosine receptors in the spinal cord suppressed neutrophil adhesion in peripheral inflammatory locations via adenosine upregulation [9, 22]. Several studies have confrmed the effects of adenosine on nervous tissue, including inhibition of the release of several classes of neurotransmitters, such as glutamate, through adenosine receptor activation [23, 24]. In the presence of inflammation, the hyperexcitability of 


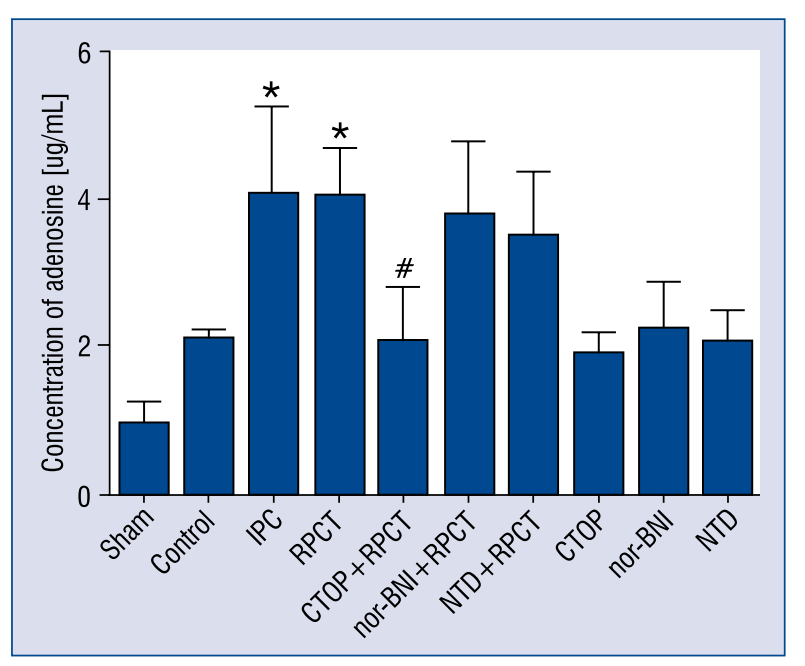

Figure 5. High-performance liquid chromatography analysis of adensoine release from the spinal cord. Values are present as mean \pm standard deviation. $\mathrm{N}=6$ in each group; ${ }^{*} \mathrm{p}<0.05 \mathrm{vs}$. control group; ${ }^{*} \mathrm{p}<0.05$ vs. remote precoditioning of trauma (RPCT) group; other abbreviations - see text.

neurons increased, and glutamate conferred this effect $[25,26]$. The concentration of glutamate in the spinal cord increased in the presence of peripheral inflammation [27]. Thus, reduced glutamate release may be one reason for the inhibitory effect of adenosine release in the spinal cord on peripheral neutrophil migration. In the present study, we found that both IPC and RPCT increased adenosine release in the spinal cord and the mu-opioid receptor antagonist inhibited the effect of RPCT on adenosine release. Moreover, changes in myocardial ICAM-1 concentrations were unaligned with changes in this adenosine release. These findings indicate that activation of mu-opioid receptors by means of RPCT increased adenosine release in the spinal cord, and this effect inhibited inflammation induced by IR injury.

Protein kinase $\mathrm{C}$ epsilon activation has been reported to mediate the cardioprotective effect of RPCT and suppress ICAM-1 expression induced by IR injury [28, 29]. To clarify the relationship of $\mathrm{PKC} \varepsilon$ and ICAM-1 expression in the protective effect of RPCT, we investigated $\mathrm{PKC} \varepsilon$ expression in myocardial cell membranes, as $\mathrm{PKC} \varepsilon$ activation can be evaluated by examining its translocation from the cytoplasm to the membrane [2]. As expected, both IPC and RPCT increased $\mathrm{PKC} \varepsilon$ activation, while CTOP inhibited the effect of RPCT. PKC $\varepsilon$ activation also reduced ICAM-1 expression in the myocardium.

\section{Limitations of the study}

There were some limitations in this study. We did not directly determine the activation of spinal opioid receptors during RPCT. However, as a nociceptive stimulus, RPCT increased endogenous opioid release, thereby activating the mu receptors. We did not directly test the spinal adenosinemediated effect with a selective adenosine receptor antagonist. In our previous study, activation of adenosine receptors had been confirmed as responsible for mediating the cardioprotective effect of the spinal opioid system [30]. In the present study, we found that enhanced adenosine release was the reason for activation of adenosine receptors.

\section{Conclusions}

In conclusion, this study demonstrated that remote preconditioning of trauma protected the myocardium against IR injury in the rat heart, and spinal mu-opioid receptors mediated this effect. The potential mechanism may be enhanced by adenosine release in the spinal cord caused by activation of mu-opioid receptors, which suppressed myocardial inflammation induced by IR injury. PKC $\varepsilon$ activation may also be involved in the mediating effect of central opioid receptors.

\section{Acknowledgements}

This study was supported by National Natural Science Foundation Of China (No. 81341014; No. 81171031; No. 81571039). Youth Culture Program of First Affiliated Hospital, Anhui Medical University, China (No. 2011kj08).

\section{Conflict of interest: None declared}

\section{References}

1. Ren X, Wang Y, Jones WK. TNF-alpha is required for late ischemic preconditioning but not for remote preconditioning of trauma. J Surg Res. 2004; 121(1): 120-129, doi: 10.1016/j.jss.2004.03.010, indexed in Pubmed: 15313385.

2. Jones WK, Fan GC, Liao S, et al. Peripheral nociception associated with surgical incision elicits remote nonischemic cardioprotection via neurogenic activation of protein kinase $\mathrm{C}$ signaling. Circulation. 2009; 120(11 Suppl): S1-S9, doi: 10.1161/CIRCULATIONAHA.108.843938, indexed in Pubmed: 19752352.

3. Wong GT, Lu Y, Mei B, et al. Cardioprotection from remote preconditioning involves spinal opioid receptor activation. Life Sci. 2012; 91(17-18): 860-865, doi: 10.1016/j.lfs.2012.08.037, indexed in Pubmed: 22982345.

4. Gross GJ, Hsu A, Gross ER, et al. Factors mediating remote preconditioning of trauma in the rat heart: central role of the cytochrome p450 epoxygenase pathway in mediating infarct size 
reduction. J Cardiovasc Pharmacol Ther. 2013; 18(1): 38-45, doi: 10.1177/1074248412437586, indexed in Pubmed: 22407888.

5. Headrick JP, See Hoe LE, Du Toit EF, et al. Opioid receptors and cardioprotection - ,opioidergic conditioning' of the heart. $\mathrm{Br}$ J Pharmacol. 2015; 172(8): 2026-2050, doi: 10.1111/bph.13042, indexed in Pubmed: 25521834.

6. Li R, Wong GTC, Wong TM, et al. Intrathecal morphine preconditioning induces cardioprotection via activation of delta, kappa, and mu opioid receptors in rats. Anesth Analg. 2009; 108(1): 23-29, doi: 10.1213/ane.0b013e3181884ba6, indexed in Pubmed: 19095826.

7. Sandner-Kiesling A, Li X, Eisenach JC. Morphine-induced spinal release of adenosine is reduced in neuropathic rats. Anesthesiology. 2001; 95(6): 1455-1459, indexed in Pubmed: 11748405.

8. Eisenach JC, Hood DD, Curry R, et al. Intrathecal but not intravenous opioids release adenosine from the spinal cord. J Pain. 2004; 5(1): 64-68, doi: 10.1016/j.jpain.2003.10.001, indexed in Pubmed: 14975380.

9. Bong GW, Rosengren S, Firestein GS. Spinal cord adenosine receptor stimulation in rats inhibits peripheral neutrophil accumulation. The role of N-methyl-D-aspartate receptors. J Clin Invest. 1996; 98(12): 2779-2785, doi: 10.1172/JCI119104, indexed in Pubmed: 8981924.

10. Yaksh T, Rudy T. Chronic catheterization of the spinal subarachnoid space. Physiology Behavior. 1976; 17(6): 1031-1036, doi: 10.1016/0031-9384(76)90029-9.

11. Zhang Ye, Irwin MG, Lu Y, et al. Intracerebroventricular administration of morphine confers remote cardioprotection-role of opioid receptors and calmodulin. Eur J Pharmacol. 2011; 656(1-3): 74-80, doi: 10.1016/j.ejphar.2011.01.027, indexed in Pubmed: 21291882.

12. Chen QL, Gu EW, Zhang L, et al. Diabetes mellitus abrogates the cardioprotection of sufentanil against ischaemia/reperfusion injury by altering glycogen synthase kinase- $3 \beta$. Acta Anaesthesiol Scand. 2013; 57(2): 236-242, doi: 10.1111/j.13996576.2012.02748.x, indexed in Pubmed: 22881281.

13. Bilgir F, Bilgir O, Calan M, et al. The levels of adhesion molecules in essential thrombocythemia. Panminerva Med. 2013; 55(4): 385-390, indexed in Pubmed: 24434346.

14. Hagberg H, Andersson P, Lacarewicz J, et al. Extracellular adenosine, inosine, hypoxanthine, and xanthine in relation to tissue nucleotides and purines in rat striatum during transient ischemia. J Neurochem. 1987; 49(1): 227-231, indexed in Pubmed: 3585332.

15. Song Y, Ye YJ, Li PW, et al. The Cardioprotective Effects of Late-Phase Remote Preconditioning of Trauma Depends on Neurogenic Pathways and the Activation of PKC and NF- $\kappa \mathrm{B}$ (But Not iNOS) in Mice. J Cardiovasc Pharmacol Ther. 2016; 21(3): 310-319, doi: 10.1177/1074248415609435, indexed in Pubmed: 26450997.

16. Chai Q, Liu J, Hu Y. Cardioprotective effect of remote preconditioning of trauma and remote ischemia preconditioning in a rat model of myocardial ischemia/reperfusion injury. Exp Ther Med. 2015; 9(5): 1745-1750, doi: 10.3892/etm.2015.2320, indexed in Pubmed: 26136887.
17. Ruiz-Meana M, Martinson EA, Garcia-Dorado D, et al. Animal ethics in cardiovascular research. Cardiovasc Res. 2012; 93(1): 1-3, doi: 10.1093/cvr/cvr289, indexed in Pubmed: 22186604.

18. Wrigley PJ, Jeong HJ, Vaughan CW. Dissociation of $\mu$ - and $\delta$-opioid inhibition of glutamatergic synaptic transmission in superficial dorsal horn. Mol Pain. 2010; 6: 71, doi: 10.1186/1744-8069-6-71, indexed in Pubmed: 20977770.

19. Chen SR, Pan HL. Blocking mu opioid receptors in the spinal cord prevents the analgesic action by subsequent systemic opioids. Brain Res. 2006; 1081(1): 119-125, doi: 10.1016/j.brainres.2006.01.053, indexed in Pubmed: 16499888.

20. DeLander GE, Hopkins CJ. Spinal adenosine modulates descending antinociceptive pathways stimulated by morphine. J Pharmacol Exp Ther. 1986; 239(1): 88-93.

21. Sawynok J, Liu XJ. Adenosine in the spinal cord and periphery: release and regulation of pain. Prog Neurobiol. 2003; 69(5): 313-340, indexed in Pubmed: 12787573.

22. Boyle DL, Moore J, Yang Li, et al. Spinal adenosine receptor activation inhibits inflammation and joint destruction in rat adjuvantinduced arthritis. Arthritis Rheum. 2002; 46(11): 3076-3082, doi: 10.1002/art.10595, indexed in Pubmed: 12428252.

23. Carlsen EM, Perrier JF. Purines released from astrocytes inhibit excitatory synaptic transmission in the ventral horn of the spinal cord. Front Neural Circuits. 2014; 8: 60, doi: 10.3389/ fncir.2014.00060, indexed in Pubmed: 24926236.

24. Corradetti R, Lo Conte G, Moroni F, et al. Adenosine decreases aspartate and glutamate release from rat hippocampal slices. Eur J Pharmacol. 1984; 104(1-2): 19-26, indexed in Pubmed: 6149943.

25. Schaible HG, Grubb BD, Neugebauer V, et al. The Effects of NMDA Antagonists on Neuronal Activity in Cat Spinal Cord Evoked by Acute Inflammation in the Knee Joint. Eur J Neurosci. 1991; 3(10): 981-991, indexed in Pubmed: 12106256.

26. Neugebauer V, Lücke T, Schaible HG. N-methyl-D-aspartate (NMDA) and non-NMDA receptor antagonists block the hyperexcitability of dorsal horn neurons during development of acute arthritis in rat's knee joint. J Neurophysiol. 1993; 70(4): 1365-1377, indexed in Pubmed: 7904298.

27. Sluka KA, Westlund KN. An experimental arthritis in rats: dorsal horn aspartate and glutamate increases. Neurosci Lett. 1992; 145(2): 141-144, indexed in Pubmed: 1361220.

28. Wei W, Wei FC, Hung LM. Diazoxide ameliorates microcirculatory disturbances through PKC-dependent pathway in I/R-injured rat cremaster muscles. J Biomed Sci. 2005; 12(3): 521-529, doi: 10.1007/s11373-005-3730-4, indexed in Pubmed: 15959630.

29. Teng JCw, Kay H, Chen Q, et al. Mechanisms related to the cardioprotective effects of protein kinase $\mathrm{C}$ epsilon (PKC epsilon) peptide activator or inhibitor in rat ischemia/reperfusion injury. Naunyn Schmiedebergs Arch Pharmacol. 2008; 378(1): 1-15, doi: 10.1007/s00210-008-0288-5, indexed in Pubmed: 18496674 .

30. Yao Lu, Wong GT, Xia $Z$, et al. Interaction between spinal opioid and adenosine receptors in remote cardiac preconditioning: effect of intrathecal morphine. J Cardiothorac Vasc Anesth. 2011; 25(3): 444-448, doi: 10.1053/j.jvca.2010.05.012, indexed in Pubmed: 20688538 . 